\title{
Twelve-year longitudinal study of respiratory status in dairy farmers
}

\author{
M. Gainet*, I. Thaon\#, V. Westeel*, H. Chaudemanche*, A.G. Venier", A. Dubiez*, \\ J.J. Laplante ${ }^{+}$and J-C. Dalphin*
}

ABSTRACT: To evaluate respiratory risk in dairy farmers, the present authors conducted a longitudinal study in the Doubs region of France.

From a cohort constituted in 1986 (T1), 157 (62.8\%) dairy farmers and 159 (63.6\%) controls were re-evaluated in 1998 (T3). The study protocol comprised a medical and occupational questionnaire, spirometric tests at both evaluations, and noninvasive measure of blood oxygen saturation with pulse oximetry $\left(\mathrm{Sp}, \mathrm{O}_{2}\right)$ at $\mathrm{T} 3$.

In 1998, the prevalence of chronic bronchitis was higher in dairy farmers. In cross-sectional analyses, all respiratory function parameters and $\mathrm{Sp}, \mathrm{O}_{2}$ were significantly lower in dairy farmers. In a multiple linear regression model, farming, age, male sex and smoking were significantly and negatively correlated with $\mathrm{Sp}, \mathrm{O}_{2}$. However, the mean annual decline in respiratory function parameters did not differ significantly between groups. After adjustment of covariables, accelerated decline in vital capacity and forced expiratory volume in one second was associated with age, smoking and male sex. Decline in vital capacity was accelerated in dairy farmers working in traditional farms and those currently foddering.

The current study demonstrates that dairy farming is associated with an increased risk of lung disorders and a decrease in blood oxygen saturation and suggests that respiratory function impairment is correlated with cumulated exposure to organic dusts.

\section{KEYWORDS: Farming, longitudinal studies, respiratory function tests}

$\mathbf{M}$ any epidemiological studies listed in recent reviews [1, 2] have shown significant and consistent associations between agricultural occupational exposure and an increase in respiratory symptoms, especially chronic bronchitis (CB). The effects of exposure on respiratory function are less clear. Crosssectional studies generally show a moderate alteration in respiratory flow in farmers. Very few longitudinal studies with control groups have been conducted to date $[3,4]$ and, in most cases, the follow-up is short and the interpretation of the results is difficult [5]. Nevertheless, accelerated decline of forced expiratory volume in one second (FEV1) and forced vital capacity has been suggested in grain handlers [6], swine confinement workers [7] and dairy farmers [4, 8]. The causes and mechanisms of this respiratory involvement, which are probably multifactorial and complex, have not yet been clearly elucidated [1]. Exposure to organic dust may have a determinant role [9]. Farmers are exposed to many organic particles that induce inflammatory or allergic reactions of the respiratory tract [10]. Theoretically, these lung disorders may have repercussions on gas exchange. To the current authors' knowledge, only one study conducted in dairy farmers [4] has shown blood oxygenation disorders.

In the present authors' region, two controlled longitudinal studies were conducted in two different geographical zones [4, 8]. A crosssectional analysis of these studies showed a significant excess in respiratory symptoms and, to a lesser degree, in bronchial obstruction among farmers compared with nonfarming controls [11, 12]. These two cohorts were re-evaluated at 5 [4] and 6 yrs [8], respectively, and the analysis revealed an excess of respiratory symptoms (particularly in CB) and bronchial obstruction among exposed subjects. These studies did not clearly reveal an accelerated decline in respiratory function among dairy farmers. This might be due to an improvement in working conditions leading to a decrease in agricultural exposure over time, as suggested by studies in grain elevator handlers [13].

The present study concerns the earlier of the two cohorts. In 1986 (T1), 250 dairy farmers were
AFFILIATIONS

Depts of ${ }^{*}$ Chest Diseases,

\#Occupational Health, and

"Biostatistics, University Hospital, and

'Mutualité Sociale Agricole of Besançon, Besançon, France.

CORRESPONDENCE

J-C. Dalphin

Dept of Chest Diseases CHU-Hôpital Jean Minjoz Boulevard Fleming

25030 Besançon Cedex France

Fax: 33381668811

E-mail: jean-charles.dalphin@ufc-

chu.univ-fcomte.fr

Received:

December 212005

Accepted after revision:

March 202007

STATEMENT OF INTEREST

None declared.

European Respiratory Journa Print ISSN 0903-1936 Online ISSN 1399-3003 
compared with 250 nonexposed control subjects, living in the same rural area [11]. The study protocol comprised a medical and occupational questionnaire and spirometry. Identical investigations were conducted on both groups (194 farmers and 155 control subjects) 6 yrs later (T2) [8].

All 500 subjects were re-evaluated in 1998 (T3) with the following objectives. 1) To re-evaluate the excess of lung disorders in dairy farmers 12 yrs years after the initial evaluation, and to confirm their consequences on blood oxygenation in another cohort. 2) To compare changes in respiratory function parameters between groups and analyse the role of agricultural exposure in these changes in the exposed group. Long-term (12 yrs) follow-up and noninvasive measurement of oxygen saturation are the main original properties of the present study.

\section{METHODS}

\section{Population}

The cohort was formed in 1986 and was composed of 250 dairy farmers of both sexes and 250 administrative employees from various agricultural companies, matched on the basis of their sex, age, smoking status and altitude [11]. The 500 subjects were selected from Mutualite Sociale Agricole (MSA) medical files by a method described previously [11]. The subjects came from six distinct districts (three located on plains at an altitude of 250-400 $\mathrm{m}$ and three located on tablelands at an altitude of $400-700 \mathrm{~m}$ ). The symptoms and lung function of both groups were compared; the characteristics of the initial population and the results of the cross-sectional comparisons were described in the current authors' previous study [11].

In 1998 (T3), 87 subjects from the initial cohort were lost to follow-up and seven had died. Among the 220 dairy farmers and the 186 control subjects remaining, each subject (not only those investigated 6 yrs earlier) was contacted individually and invited to participate in the third identical investigation. Subjects who agreed were re-evaluated at the same time of year as the two previous analyses. They were examined between 08:30-11:30 h near their home. The medical questionnaire and spirometric tests were the same as those used in T1 and T2; they were completed along with an occupational questionnaire, blood oxygen saturation and cardiac frequency (fC) measures.

The current study respects ERS principles for research involving humans and received approval from the local ethics committee (Besançon, France).

\section{Questionnaires}

Medical questionnaires were sent by mail 10 days before the scheduled medical examination and were collected during check-up examinations. They were read and completed, when necessary (in the case of missing data), by the same investigator as in 1986 (T1) and 1992 (T2). The questionnaire was based on the American Thoracic Society (ATS) questionnaire [14] and the long version of the European Community Respiratory Health Survey questionnaire [15]. Questions concerning smoking habits, respiratory symptoms and allergy, as well as the definition of $\mathrm{CB}$, dyspnoea and asthma, have been given previously [11]. The occupational questionnaire, used in previous studies $[16,17]$, was completed during the examination. It was performed by the authors in collaboration with engineers and technicians from the local Dept of Agriculture (Besançon, France) and MSA technicians. The main professional exposure indicators concerned the size of the farm, the size of the herd and the method of storing and drying fodder. Exposure to fodder was assessed in terms of handling, the farm's modernisation and the average time spent in the barn. Fodder handling was measured in two ways, first in terms of actual handling and secondly in terms of bale-yrs. There were three handling categories: 1) never having handled fodder, 2) having stopped handling fodder $\geqslant 1 \mathrm{yr}$ before completing the questionnaire; and 3) currently handling fodder. Bale-yrs were defined by the number of average density bales of hay (or equivalent when farmers used other methods of storage) fed to cattle per day, multiplied by the number of years of foddering. The modernisation of farms was classified as follows. Traditional: fodder in bulk or packed in average density bales, no drying method for the fodder and no electric ventilation of the barn. Modernised: fodder packed in round bales, no drying method and no electric ventilation. Modern: drying method of fodder and electric ventilation of the barn. These exposure indicators concerned the winter of 1997 and the 12 yrs of follow-up (T1-T3).

\section{Respiratory function tests}

Respiratory function tests were performed by the same investigator as 6 and $12 \mathrm{yrs}$ earlier, according to ATS recommendations [18], with a portable pneumotachograph (Autospiro Minato, AS 500; Medical Science Company Ltd, Osaka, Japan). Three measures of slow vital capacity (VC), FEV1, mean forced expiratory flow between 25 and $75 \%$ of forced VC (FEF25-75\%) and peak expiratory flow were performed, and the best values selected. The spirometer was calibrated daily for atmospheric pressure, hygrometry and temperature. The values were expressed as absolute values and as percentages of European Community for Steel and Coal reference values, calculated in relation to sex, age and height [19].

\section{Oximetry data}

Arterial oxygen saturation $\left(\mathrm{Sa}_{2} \mathrm{O}_{2}\right)$ and $f C$ were evaluated for each subject with a finger pulse oximeter (Onyx ${ }_{\circledR}$ model 9500; Nonin Medical Inc., Plymouth, MN, USA). Patients were seated for $\geqslant 15$ min before three measurements were taken at 30 -s intervals on the left index finger of each subject. The highest value of blood oxygen saturation measured with pulse oximetry $\left(\mathrm{Sp}, \mathrm{O}_{2}\right)$ was retained with the corresponding $f \mathrm{C}$. The right index finger was used in left-handed subjects. In case of an injured nail, another finger on the same hand was used. It was also ensured that subjects were not wearing nail polish; if they were it was removed. Measures were taken for both farmers and controls after spending $\geqslant 30 \mathrm{~min}$ in heated rooms. The pulse oximeter was tested weekly for accuracy by comparing $\mathrm{Sp}_{\mathrm{p}} \mathrm{O}_{2}$ with the $\mathrm{Sa}_{1} \mathrm{O}_{2}$ of arterial blood gases.

\section{Data analysis}

First, a cross-sectional analysis of the 1998 data was performed to compare dairy farmers with control subjects. A multiple logistic regression was used to compare the odds ratios for respiratory symptoms in order to correct for imbalances in age, sex and smoking. Relationships between lung function, $\mathrm{Sp}_{\mathrm{p}} \mathrm{O}_{2}$ 
and $f C$, and farming were assessed using multiple linear regression models. Adjustments were made for smoking (current smoker, ex-smoker or nonsmoker) in the respiratory function model, and for age (as a continuous variable), sex (female $=0$, male $=1$ ), smoking (pack-yrs), FEV1/VC ratio (as a continuous variable) and altitude (plain $=0$, tableland $=1$ ) in the $\mathrm{Sp}, \mathrm{O}_{2}$ models. Farming was added to a model analysing $\mathrm{Sp}, \mathrm{O}_{2}$. Secondly, a longitudinal analysis of respiratory function was performed. The effect of farming on the annual change in respiratory parameters between T1 and T3 (1998 value-1986 value/number of years between $\mathrm{T} 1$ and $\mathrm{T} 3$ examinations) was tested by using a multiple linear regression model adjusted for the 1998 value of farming, age, sex, smoking, altitude and reevaluation in 1992 (not re-evaluated $=0$, re-evaluated $=1$ ). Thirdly, a cross-sectional analysis was performed on T3 data to compare the annual change in respiratory parameters and blood oxygen saturation with occupational exposure indicators in 1998 and their evolution between T1 and T3. Univariate analyses were used, including unpaired t-test and ANOVA for discrete variables and simple linear regression for continuous variables. All tests were two-sided and p-values $\leqslant 0.05$ were considered statistically significant.

\section{RESULTS}

\section{Population characteristics}

In 1986 (T1), the initial cohort included 500 subjects. By 1998 (T3), 87 subjects had been lost to follow-up and seven had died. Among the 220 dairy farmers and the 186 control subjects remaining, $316(77.8 \%)$ agreed to participate in the present study and were re-evaluated. Among the 90 subjects who were not re-evaluated, 66 (37 dairy farmers and 29 controls) were contacted by telephone and answered a questionnaire. Reasons

\section{TABLE 1 Description of the study population in 1998}

\begin{tabular}{lccc} 
& Dairy farmers & Controls & p-value ${ }^{\#}$ \\
\hline Subjects & $157(49.7)$ & $159(50.3)$ & \\
Age yrs & $50.8 \pm 9.3$ & $50.8 \pm 8.6$ & NS \\
$25-34$ & $5(3.2)$ & 0 & NS \\
$35-44$ & $32(20.4)$ & $38(23.9)$ & NS \\
$45-54$ & $69(43.9)$ & $79(49.7)$ & NS \\
$55-64$ & $35(22.3)$ & $25(15.7)$ & NS \\
$>64$ & $16(10.2)$ & $17(10.7)$ & NS \\
Sex & & & \\
Male & $88(56.1)$ & $94(59.1)$ & NS \\
Female & $69(43.9)$ & $65(40.9)$ & NS \\
Smoking & & & \\
Smokers & $23(14.6)$ & $34(21.4)$ & $<0.05$ \\
Ex-smokers & $42(26.8)$ & $59(37.1)$ & $<0.05$ \\
Nonsmokers & $92(58.6)$ & $66(41.5)$ & $<0.05$ \\
Pack-yrs & $15.6 \pm 12$ & $13.5 \pm 11.7$ & NS \\
Geography & & & \\
Plain & $89(56.7)$ & $144(90.6)$ & $<0.001$ \\
Tableland & $68(43.3)$ & $15(9.4)$ & $<0.001$ \\
\hline
\end{tabular}

Data are presented as $\mathrm{n}(\%)$ or mean $\pm \mathrm{SD}$, unless otherwise stated. NS nonsignificant. \#: Chi-squared test used for qualitative variables and t-test used for quantitative variables; ${ }^{`}$ : smokers and ex-smokers. for refusal included lack of time, lack of interest in the study and inability to attend the medical evaluation for occupational reasons. Only seven cases refused for medical reasons (five dairy farmers and two controls). Individual characteristics, respiratory symptoms and lung function at $\mathrm{T} 1$ were compared between re-evaluated subjects and subjects not re-evaluated. Except for a decrease in females re-evaluated in the control population in $1998(\mathrm{p}<0.05)$, no significant difference was found for age, respiratory symptoms and function. Among the population re-evaluated in 1998, 246 subjects (133 farmers and 113 controls) had been re-evaluated in 1992. The individual characteristics of the study population at T3 are presented in table 1. Statistically significant differences between both groups were observed for smoking $(p<0.05)$ and altitude $(p<0.001)$. The occupational characteristics in dairy farmers at T3 are detailed in table 2.

\section{Cross-sectional analyses}

The prevalence of asthma, asthma-related symptoms and dyspnoea were the same in both groups. The prevalence of

\begin{tabular}{|c|c|c|}
\hline TABLE 2 & \multicolumn{2}{|c|}{$\begin{array}{l}\text { Occupational characteristics in dairy farmers in } \\
1998\end{array}$} \\
\hline Subjects & & 155 \\
\hline \multicolumn{3}{|l|}{ Activity level } \\
\hline Active & & $120(77.4)$ \\
\hline Retired, still & working on a farm & $13(8.4)$ \\
\hline Retired, no I & onger working on a farm & $22(14.2)$ \\
\hline \multicolumn{3}{|c|}{ Farm characteristics } \\
\hline \multicolumn{3}{|c|}{ Modernisation } \\
\hline Traditiona & & $14(9)$ \\
\hline Modernise & & $61(39.4)$ \\
\hline Modern & & $80(51.6)$ \\
\hline Size hectare & & $60.5 \pm 27.1$ \\
\hline Size of fodd & r lands hectares & $31.5 \pm 16.7$ \\
\hline Herd size & & $67.2 \pm 32.9$ \\
\hline \multicolumn{3}{|c|}{ Fodder storage method } \\
\hline Bulk & & $14(9)$ \\
\hline Packed in a & erage density bale & $66(42.6)$ \\
\hline Packed in ro & und bales & $61(39.4)$ \\
\hline Barn drying & & $67.2(32.9)$ \\
\hline \multicolumn{3}{|c|}{ Fodder handling } \\
\hline Never & & $37(23.9)$ \\
\hline Stopped $\geqslant 1$ & & $30(19.4)$ \\
\hline Currently & & $88(56.8)$ \\
\hline \multicolumn{3}{|l|}{ Bale-yrs } \\
\hline 1986-1998 & & $265.8 \pm 282.4$ \\
\hline Cumulative & & $584.7 \pm 590.4$ \\
\hline Time spent in & barn 1986-1998 h.yr ${ }^{-1}$ & $897.4 \pm 385.9$ \\
\hline \multicolumn{3}{|c|}{$\begin{array}{l}\text { Prevention system against exposure } \\
\text { to micro-organisms } 1986-1998\end{array}$} \\
\hline Yes & & $63(41.4)$ \\
\hline No & & $89(58.6)$ \\
\hline \multicolumn{3}{|c|}{ Evolution of exposure 1986-1998 } \\
\hline Unchanged & & $62(40.3)$ \\
\hline Increased & & $32(20.8)$ \\
\hline Decreased & & $60(39)$ \\
\hline
\end{tabular}

Data are presented as $n, n(\%)$ or mean $\pm S D$ 




Data are presented as $\mathrm{n}$ or mean $\pm \mathrm{SD}$, unless otherwise stated. Spirometric values were transformed into a percentage of European Community for Steel and Coal reference values and calculated in relation to sex, age and height. All values take into account atmospheric pressure, hygrometry and temperature. VC: vital capacity; FEV1: forced expiratory volume in one second; FEF $25-75 \%$ : mean forced expiratory flow between 25 and $75 \%$ of forced VC; NS nonsignificant. ${ }^{\#}$ : multiple linear regression adjusted for smoking; ": multiple linear regression adjusted for age, sex (female $=0$, male $=1$ ), smoking pack-yrs, FEV 1 NC and altitude (plain $=0$, tableland $=1$ ).

atopy was lower in farmers after adjustment for age, sex and smoking (36.9 versus 50.3\% (odds ratio $0.57,95 \%$ confidence interval 0.36-0.91)). Conversely, the prevalence of $\mathrm{CB}$ was significantly higher in dairy farmers after adjustment for the same covariables (17.2 versus $5.7 \%(2.22,1.09-4.53))$. The results of respiratory function and $\mathrm{Sp}, \mathrm{O}_{2}$ at $\mathrm{T} 3$ are shown in table 3 . All respiratory function parameters were significantly lower in dairy farmers. The $\mathrm{S}_{\mathrm{p}} \mathrm{O}_{2}$ was also lower $(\mathrm{p}<0.001)$ among dairy farmers, with a mean difference of $0.7 \%$. In a linear multiple regression model, farming, age and smoking were inversely correlated with $S \mathrm{p}, \mathrm{O}_{2}(\mathrm{p}<0.025$; table 4$)$. A positive correlation was found between $\mathrm{FEV} 1 / \mathrm{VC}$ ratio and $\mathrm{Sp}_{\mathrm{p}} \mathrm{O}_{2}(\mathrm{p}<0.001)$. Blood oxygen saturation was significantly lower among males $(\mathrm{p}<0.001)$.

\section{Longitudinal analyses}

The longitudinal analysis of pulmonary function tests was performed on 289 subjects ( 145 dairy farmers and 144 controls) whose explorations were concordant with the ATS criteria [18] at both T1 and T3. Mean annual changes in respiratory function parameters between 1986 and 1998 are presented in table 5. The mean annual decline in VC and FEV1 was 23.7 and $15.09 \mathrm{~mL} \cdot \mathrm{yr}^{-1}$, respectively, for the whole cohort. The decline in lung function was similar in both groups (table 6). The factors associated with an accelerated decline in VC and in FEV1 were age $(p<0.001)$, smoking $(p<0.001$ and $p<0.01$ for FEV1 and VC, respectively) and male sex $(p<0.001)$. The subjects re-evaluated in 1992 (133 dairy farmers re-evaluated at $\mathrm{T} 1, \mathrm{~T} 2$ and T3) had a lower decline in VC $(\mathrm{p}<0.001)$ than those only re-evaluated in 1998. $\begin{array}{cl}\text { TABLE } 4 & \begin{array}{l}\text { Multiple regression model for arterial oxygen } \\ \text { saturation measured by pulse oximetry }\left(\mathrm{Sp}, \mathrm{O}_{2}\right)\end{array}\end{array}$

\begin{tabular}{lcc} 
Independent variables & \multicolumn{2}{c}{${\mathrm{Sp}, \mathrm{O}_{2}}$} \\
\cline { 2 - 3 } & Coefficient & p-value \\
\hline Farming & $-0.54 \pm 0.16$ & $<0.001$ \\
Male sex & $-0.75 \pm 0.16$ & $<0.001$ \\
Age yrs & $-0.02 \pm 0.01$ & $<0.001$ \\
Smoking & $-0.01 \pm 0.01$ & $<0.025$ \\
FEV1/VC & $0.05 \pm 0.01$ & $<0.001$ \\
Altitude (tableland) & $-0.24 \pm 0.18$ & $\mathrm{NS}$ \\
Intercept & 94.78 & \\
$\mathbf{r}^{2}$ & 0.26 & \\
\hline
\end{tabular}

Data are presented as mean cofficient \pm SEM, unless otherwise stated. NS: nonsignificant. All variables were included simultaneously in the model; each coefficient and p-value is controlled for all other covariates. Age, smoking packyrs and forced expiratory volume in one second (FEV1)/vital capacity (VC) are continuous variables. Farming: $\mathrm{no}=0$, yes $=1$; sex: female $=0$, male $=1$; altitude: plain $=0$, tableland $=1$.

\section{Relationship between occupational exposure and respiratory parameters: lung function decline and $\mathrm{Sp}, \mathrm{O}_{2}$}

Results are detailed in table 7. Dairy farmers who were officially retired showed a significant decline in VC $(p<0.001)$ and FEV1 $(p<0.025)$ and a decrease in $S p, O_{2}$ $(\mathrm{p}<0.001)$. Decline in lung function was significantly accelerated in dairy farmers working on traditional farms (for VC $\mathrm{p}<0.05)$, and in those already having handled fodder $(\mathrm{p}<0.001)$. Foddering had a deleterious effect on $\mathrm{Sp}_{\mathrm{p}} \mathrm{O}_{2}$. The mean duration of exposure was significantly associated with the decline in FEV1 $(\mathrm{p}<0.05)$ and with a decrease in $S \mathrm{p}, \mathrm{O}_{2}$ $(p<0.025)$. In a multiple regression model, after adjustment for these same covariables, the decline in VC was accelerated $(p<0.001)$ in dairy farmers who had stopped handling fodder and who were currently foddering versus those who had never handled fodder.

\section{TABLE 5 Mean annual changes in respiratory function parameters between 1986 and 1998}

\begin{tabular}{|c|c|c|}
\hline & Farmers & Controls \\
\hline Subjects $n$ & 145 & 144 \\
\hline Time between surveys yrs & $11.9 \pm 0.2$ & $11.7 \pm 0.2$ \\
\hline$\Delta \mathrm{VC} \mathrm{mL} \cdot \mathrm{yr}^{-1}$ & $-20.61 \pm 37.7$ & $-26.97 \pm 43.7$ \\
\hline$\Delta F E V_{1} \mathrm{~mL} \cdot \mathrm{yr}^{-1}$ & $-13.2 \pm 32.8$ & $-17.0 \pm 31.5$ \\
\hline$\Delta \mathrm{FEV}_{1} / \mathrm{VC} \% \cdot \mathrm{yr}^{-1}$ & $0.08 \pm 0.57$ & $0.00 \pm 0.57$ \\
\hline$\Delta \mathrm{FEF}_{25-75 \% \mathrm{~mL} \cdot \mathrm{yr}^{-1}}$ & $-19.5+58.3$ & $-23.1+67.4$ \\
\hline
\end{tabular}

Data are presented as mean $\pm \mathrm{SD}$, unless otherwise stated. $\Delta$ : change; VC: vital capacity; FEV1: forced expiratory volume in one second; FEF25-75\%: mean forced expiratory flow between 25 and $75 \%$ of forced VC. $\Delta=(1998$ value -1986 value)/(number of yrs between $\mathrm{T} 1$ and $\mathrm{T} 3$ examinations). 
TABLE 6 Regression models for annual changes in lung function

\begin{tabular}{|c|c|c|c|c|}
\hline Independent variables & $\Delta \mathrm{VC}$ & $\Delta \mathrm{FEV}_{1}$ & $\Delta \mathrm{FEV}_{1} / \mathrm{VC}$ & $\Delta \mathrm{FEF} 25-75 \%$ \\
\hline Farming & $2.92 \pm 5.02$ & $-1.75 \pm 4.08$ & $-1.18 \pm 0.07^{\star \star \star}$ & $-6.74 \pm 8.20$ \\
\hline Smoking & $-0.43 \pm 0.22^{\star \star}$ & $-0.39 \pm 0.18^{\star \star *}$ & $-0.0016 \pm 0.003$ & $-0.32 \pm 0.36$ \\
\hline Male & $-15.04 \pm 4.98^{* * *}$ & $-9.54 \pm 4.06^{\star * *}$ & $-0.04 \pm 0.07$ & $-9.10 \pm 8.17$ \\
\hline Altitude & $13.58 \pm 5.56^{\star \star \star}$ & $3.69 \pm 4.52$ & $0.25 \pm 0.08$ & $-2.28 \pm 9.10$ \\
\hline$r^{2}$ & 0.13 & 0.07 & 0.05 & 0.02 \\
\hline
\end{tabular}

Data are presented as mean coefficient \pm SEM, unless otherwise stated. $\Delta$ : change; VC: vital capacity; FEV1: forced expiratory volume in one second; FEF25-75\%: mean forced expiratory flow between 25 and $75 \%$ of forced VC. All listed variables were included simultaneously in the models. Each coefficient and p-value was controlled for by all other covariates. Age and smoking are continuous variables. Farming: controls $=0$, farmers $=1$; altitude: plain $=0$, tableland $=1$; not re-evaluated in $1992=0$, re-evaluated in $1992=1 .{ }^{*}: p<0.025 ; *: p<0.05 ; * *: p<0.01 ; * *: p<0.001$.

\section{DISCUSSION}

The results of the present study are consistent with those of the 1986 and 1992 cross-sectional analyses [8, 11], and with those of other studies conducted in the same region [4, 12]. Dairy farmers present a persistent excess of $\mathrm{CB}$ with bronchial obstruction. These lung disorders have a significant impact on blood oxygenation. Conversely, an accelerated decline of respiratory function parameters was not observed in this cohort, possibly due to a decrease in exposure with over time.

In the current study, the prevalence of $\mathrm{CB}$ was higher in dairy farmers, but the prevalence of asthma was not. In addition, the

TABLE 7 Univariate analysis of annual decline in respiratory function between 1986 and 1998 and occupational exposure

$$
\mathrm{Sp}, \mathrm{O}_{2} \%
$$

\begin{tabular}{|c|c|c|c|c|c|c|c|c|c|}
\hline \multicolumn{10}{|l|}{ Activity level } \\
\hline Active & $96.86(1.37)^{\bullet}$ & $-14.71 * \star \star$ & 35.31 & -10.30 & $30.22^{+}$ & 0.05 & 053 & 22.52 & $57.35^{\star}$ \\
\hline Retired, still working on a farm ${ }^{\#}$ & $94.84(2.03)^{\bullet}$ & -55.66 & $49.94^{\star \star \star}$ & -42.82 & $36.55^{+}$ & -0.03 & 0.64 & 40.71 & $52.28 *$ \\
\hline Retired, no longer working on a farm & $96.66(2.22)^{\bullet}$ & -29.65 & $30.88^{\star \star \star}$ & -10.02 & $34.59^{+}$ & 0.25 & 0.71 & 8.32 & $54.16^{*}$ \\
\hline \multicolumn{10}{|l|}{ Farm characteristics } \\
\hline \multicolumn{10}{|l|}{ Modernisation } \\
\hline Traditional & $96.84(1.82)$ & -26.88 & $27.42^{*}$ & -16.28 & 27.06 & 0.81 & 6.12 & -17.64 & 62.45 \\
\hline Modernised & $96.63(1.47)$ & -22.91 & $32.25^{\star}$ & -18.4 & 30.67 & 0.86 & 6.29 & -24.72 & 54.64 \\
\hline Modern & $95.78(1.12)$ & -4.21 & $32.32^{*}$ & -5.33 & 30.1 & -1.00 & 4.74 & -13.57 & 64.99 \\
\hline Size of herd & $0.03(1.65)$ & 0.02 & 37.9 & 0.08 & 32.6 & 0.09 & 0.56 & 0.18 & $57.49^{*}$ \\
\hline \multicolumn{10}{|l|}{ Fodder handling } \\
\hline Never & $97.59(1.23)^{\bullet}$ & -19.20 & $24.81^{\star \star \star}$ & -7.67 & $19.96^{*}$ & 2.66 & 5.77 & -3.23 & 51.54 \\
\hline Stopped for $\geqslant 1 \mathrm{yr}$ & $96.63(1.47)^{\bullet}$ & -18.24 & $28.92^{\star \star \star}$ & -15.94 & $27.66^{\star}$ & -0.13 & 5.57 & -28.67 & 62.54 \\
\hline Currently & $96(2.29) \bullet$ & -41.86 & $33.77^{\star \star \star}$ & -27.29 & $37.21^{*}$ & 1.03 & 7.28 & -13.57 & 57.57 \\
\hline Time spent in barn & $-0.19(1.65)^{+}$ & -0.04 & 30.34 & -0.16 & $28.73^{*}$ & -0.14 & 6.06 & -0.17 & $59.63^{*}$ \\
\hline \multicolumn{10}{|l|}{ Prevention system } \\
\hline Yes & $96.52(1.81)$ & -16.36 & 35.48 & -13.11 & 31.29 & 0.03 & 0.55 & -19.63 & 58.88 \\
\hline No & $96.73(1.55)$ & -23.55 & 39.71 & -13.57 & 33.95 & 0.10 & 0.58 & -21.14 & 57.06 \\
\hline \multicolumn{10}{|l|}{ Evolution of exposure } \\
\hline Unchanged & $96.83(1.40)$ & -20.37 & 26.92 & -16.27 & 23.83 & 0.17 & 5.35 & -28.19 & 55.51 \\
\hline Increased & $96.75(1.36)$ & -18.44 & 30.34 & -14.64 & 30.59 & 0.48 & 6.57 & -24.85 & 65.85 \\
\hline Decreased & $96.44(2.01)$ & -28.78 & 33.51 & -16.76 & 32.94 & 1.34 & 6.58 & -11.20 & 60.54 \\
\hline
\end{tabular}

\begin{tabular}{|c|c|c|c|c|c|c|c|c|c|}
\hline \multicolumn{10}{|l|}{ Activity level } \\
\hline Active & $96.86(1.37)^{\bullet}$ & $-14.71 * \star \star$ & 35.31 & -10.30 & $30.22^{+}$ & 0.05 & 053 & 22.52 & $57.35^{\star}$ \\
\hline Retired, still working on a farm ${ }^{\#}$ & $94.84(2.03)^{\bullet}$ & -55.66 & $49.94^{\star \star \star}$ & -42.82 & $36.55^{+}$ & -0.03 & 0.64 & 40.71 & $52.28 *$ \\
\hline Retired, no longer working on a farm & $96.66(2.22)^{\bullet}$ & -29.65 & $30.88^{\star \star \star}$ & -10.02 & $34.59^{+}$ & 0.25 & 0.71 & 8.32 & $54.16^{*}$ \\
\hline \multicolumn{10}{|l|}{ Farm characteristics } \\
\hline \multicolumn{10}{|l|}{ Modernisation } \\
\hline Traditional & $96.84(1.82)$ & -26.88 & $27.42^{*}$ & -16.28 & 27.06 & 0.81 & 6.12 & -17.64 & 62.45 \\
\hline Modernised & $96.63(1.47)$ & -22.91 & $32.25^{\star}$ & -18.4 & 30.67 & 0.86 & 6.29 & -24.72 & 54.64 \\
\hline Modern & $95.78(1.12)$ & -4.21 & $32.32^{*}$ & -5.33 & 30.1 & -1.00 & 4.74 & -13.57 & 64.99 \\
\hline Size of herd & $0.03(1.65)$ & 0.02 & 37.9 & 0.08 & 32.6 & 0.09 & 0.56 & 0.18 & $57.49^{*}$ \\
\hline \multicolumn{10}{|l|}{ Fodder handling } \\
\hline Never & $97.59(1.23)^{\bullet}$ & -19.20 & $24.81^{\star \star \star}$ & -7.67 & $19.96^{*}$ & 2.66 & 5.77 & -3.23 & 51.54 \\
\hline Stopped for $\geqslant 1 \mathrm{yr}$ & $96.63(1.47)^{\bullet}$ & -18.24 & $28.92^{\star \star \star}$ & -15.94 & $27.66^{\star}$ & -0.13 & 5.57 & -28.67 & 62.54 \\
\hline Currently & $96(2.29) \bullet$ & -41.86 & $33.77^{\star \star \star}$ & -27.29 & $37.21^{*}$ & 1.03 & 7.28 & -13.57 & 57.57 \\
\hline Time spent in barn & $-0.19(1.65)^{+}$ & -0.04 & 30.34 & -0.16 & $28.73^{*}$ & -0.14 & 6.06 & -0.17 & $59.63^{*}$ \\
\hline \multicolumn{10}{|l|}{ Prevention system } \\
\hline Yes & $96.52(1.81)$ & -16.36 & 35.48 & -13.11 & 31.29 & 0.03 & 0.55 & -19.63 & 58.88 \\
\hline No & $96.73(1.55)$ & -23.55 & 39.71 & -13.57 & 33.95 & 0.10 & 0.58 & -21.14 & 57.06 \\
\hline \multicolumn{10}{|l|}{ Evolution of exposure } \\
\hline Unchanged & $96.83(1.40)$ & -20.37 & 26.92 & -16.27 & 23.83 & 0.17 & 5.35 & -28.19 & 55.51 \\
\hline Increased & $96.75(1.36)$ & -18.44 & 30.34 & -14.64 & 30.59 & 0.48 & 6.57 & -24.85 & 65.85 \\
\hline Decreased & $96.44(2.01)$ & -28.78 & 33.51 & -16.76 & 32.94 & 1.34 & 6.58 & -11.20 & 60.54 \\
\hline
\end{tabular}

$\frac{\mathrm{FEV}_{1} / \mathrm{VC}}{\Delta \quad \mathrm{mL} \cdot \mathrm{yr}^{-1}}$

FEF25-75\%

Data are presented as $\mathrm{n}(\%)$, unless otherwise stated. $\mathrm{Sp}, \mathrm{O}_{2}$ : arterial oxygen tension as measured by pulse oximetry; VC: vital capacity; FEV1: forced expiratory volume in one second; FEF25-75\%: mean forced expiratory flow between 25 and $75 \%$ of forced VC; $\Delta$ : change. * : Some farmers were officially retired in 1998 but continued to work by helping their spouse or children. ${ }^{\bullet}: \mathrm{p}<0.0001 ;{ }^{+}: \mathrm{p}<0.025 ;{ }^{*}: \mathrm{p}<0.05 ;{ }^{\star} * * \mathrm{p}<0.001$; using Chi-squared and t-tests for qualitative and quantitative variables, respectively. 
prevalence of atopy was lower in exposed subjects. These results concur with studies recently reviewed [20]. In crosssectional analyses, all respiratory function parameters were significantly lower among farmers, particularly FEV1 and FEV1/VC ratio, with the same difference between the two groups as 12 yrs earlier at T1 [11].

One of the unique properties of the present study was the measurement of $\mathrm{Sp}_{\mathrm{p}} \mathrm{O}_{2}$ as, to date, there have been no published recommendations for the use of pulse oximeter in epidemiological studies. A recent study evaluating the potential relationship between air pollution and $\mathrm{Sa}_{2} \mathrm{O}_{2}$ in elderly adults suggested that the accuracy and reproducibility of $\mathrm{Sp}, \mathrm{O}_{2}$ measures allowed the use of a pulse oximeter for epidemiological studies [21]. In the current study, a recent pulse oximeter was used, in accordance with the 1995 European regulations. The best of three measures was retained. It was ensured that subjects were not wearing nail polish [22]; if they were it was removed. The current results demonstrate that $\mathrm{Sp}, \mathrm{O}_{2}$ was lower in dairy farmers $(\mathrm{p}<0.001)$. Fodder handling and a longer time spent in the barn were negatively associated with $S \mathrm{p}, \mathrm{O}_{2}$. In a recent study, the first to measure $S_{\mathrm{p}, \mathrm{O}_{2}}$ in farmers, the current authors observed the same difference of $S \mathrm{p}, \mathrm{O}_{2}$ between farmers and nonexposed subjects groups $(0.7 \%)$, but with a lower level of significance [4]. In the current study, the fact that $\mathrm{Sp}_{\mathrm{p}} \mathrm{O}_{2}$ was, as expected, negatively correlated to smoking and age, and positively correlated to all respiratory function parameters argues for both the accuracy and the relevance of the tool. After adjustment for FEV1/VC ratio, farming remained associated with a decreased $\mathrm{Sp}_{\mathrm{p}} \mathrm{O}_{2}$; this suggests that mechanisms other than bronchial obstruction are involved. Desaturation can be due to alveolitis (possibly infraclinical) as in hypersensitivity pneumonitis. Indeed, this affection is frequent in this region of France [23]. Dairy farmers are usually exposed to a great quantity of organic particles, including endotoxins, which may induce inflammatory reactions of alveoli and small airways, and therefore alter the alveolo-capillary diffusion [8, 24-26]. This may partially explain the decrease in $\mathrm{Sp}, \mathrm{O}_{2}$. However, it cannot be totally excluded that more callous hands in farmers play a role in the observed results. As the present study was conducted in winter and spring, pulse oximetry readings may also been affected by physiological processes, such as vasoconstriction in reaction to the cold. However, in the present study, subjects first completed the questionnaires with the physician, then the $\mathrm{Sp}, \mathrm{O}_{2}$ measures were performed after at least $30 \mathrm{~min}$ spent in a heated room. Furthermore, both farmers and controls were investigated in the same heated rooms. Subjects accustomed to working outdoors also presented with cold acclimatisation in the hands. Among these outdoor workers, cold vasodilatation occurred earlier than in nonacclimatised subjects working indoors [27, 28]. Hence, in a cold room, higher $\mathrm{Sp}, \mathrm{O}_{2}$ measures should have been observed in farmers than in controls, given earlier vasodilatation due to cold acclimatisation in farmers.

Cross-sectional results in 1986 (T1) showed a significant bronchial obstruction in dairy farmers which might predict an accelerated decline in lung function in exposed subjects. However, no such accelerated decline in farmers was observed, consistent with previous results reported in the European Community Respiratory Health Survey (ECRHS) [29]. In the ECRHS, subjects exposed to dust, gases and fumes during the follow-up did not have accelerated decline in FEV1, although they did have an excess of chronic phlegm similar to the present study subjects. Various hypotheses have been stated to explain these discrepancies between longitudinal and cross-sectional results [30-32]. In the current study, ill subjects were not lost in follow-up. Respiratory function parameters at T1 in re-evaluated subjects and subjects not re-evaluated, in dairy farmers and controls, were similar. Therefore, a selective follow-up can be excluded, but a selection effect in farmers at inclusion cannot be excluded. In the current study, the mean annual decline was higher between T1 and T2 than between T1 and T3 [8]. The deceleration in decline might be explained by a learning effect $[30,31]$ or by systematic errors in measurements of lung function at T2 or T3. In the present study, mean annual changes were positively correlated with smoking and age. This shows the relevance of the current measures and, therefore, current results. GLINDMEYER et al. [31] also suggested that past noxious exposures may influence sectional analyses, whereas longitudinal analyses are only sensitive to influences that continue to affect annual decline during the study period. The decrease in respiratory risk exposure over time might explain this absence of accelerated decline. In the current study, occupational characteristics in farmers showed that, between 1986 and 1998, 40\% of the farmers claim to have reduced their occupational exposure, $41.4 \%$ developed prevention and, in 1998, 40\% worked on a modern farm. Furthermore, subjects with bronchial obstruction at T1 (1986) might have been more likely to decrease their exposure and to develop prevention. The respiratory function in farmers had probably decreased significantly before 1986, when occupational exposure was greater. Furthermore, during the first 6 yrs [8], the decline of respiratory function parameters in dairy farmers accelerated slightly, whereas it slowed down over the following 6 yrs. The present authors speculate that this type of course over the follow-up period may result from a decrease in the offending exposure. Decline in respiratory function parameters seemed to decrease in dairy farmers foddering in modern farms, especially those with a barn drying system (table 7). Previous studies have suggested that the barn drying fodder system is an important criterion of modernisation, known to lower exposure to aero-contaminants by reducing the proliferation of micro-organisms [16, 33]. Another recent study has shown working on a modern farm to be associated with a decrease in risk of lung impairment [34]. In addition, accelerated decline in respiratory function was correlated with fodder handling and average time spent in the barn $(p<0.001$ and $p<0.05$ for the decline in FEV1 and decline in FEF25-75\%, respectively). All these relationships between exposure and lung function impairment fit with the current authors' speculation that the observed improvement of lung function in farmers is related to a significant improvement in working conditions over time.

\section{Conclusion}

The present results demonstrate an excess of chronic bronchitis with obstructive airway disorders and a decrease in blood oxygen saturation in farmers. No significant accelerated decline in respiratory function parameters was found in dairy farmers, possibly due to a decrease in the risk of occupational exposure over time. However, in farmers, an accelerated decline in respiratory function was correlated with fodder handling and the average time spent in the barn. 


\section{REFERENCES}

1 American Thoracic Society. Respiratory health hazards in agriculture. Am J Respir Crit Care Med 1998; 158: Suppl. 5, S1-S76.

2 Iversen M, Kirychuk S, Drost H, Jacobson L. Human health effects of dust exposure in animal confinement buildings. $J$ Agric Saf Health 2000; 6: 283-288.

3 Iversen M. Predictors of long-term decline of lung function in farmers. Monaldi Arch Chest Dis 1997; 52: 474-478.

4 Chaudemanche $\mathrm{H}$, Monnet E, Westeel V, et al. Respiratory status in dairy farmers in France; cross sectional and longitudinal analyses. Occup Environ Med 2003; 60: 858-863.

5 American Thoracic Society-European Respiratory Society longitudinal data analysis workshop. Am J Respir Crit Care Med 1996; 154: Suppl. 6, S277-S284.

6 Enarson DA, Vedal S, Chan-Yeung M. Rapid decline in FEV1 in grain handlers. Am Rev Respir Dis 1985; 132: 814-817.

7 Senthilselvan A, Dosman JA, Kirychuk SP, et al. Accelerated lung function decline in swine confinement workers. Chest 1997; 111: 1733-1741.

8 Dalphin JC, Maheu MF, Dussaucy A, et al. Six year longitudinal study of respiratory function in dairy farmers of the Doubs province. Eur Respir J 1998; 11: 1287-1293.

9 Christiani DC. Organic dust exposure and chronic airway disease. Am J Respir Crit Care Med 1996; 154: 833-834.

10 Rylander R, Peterson Y. Causative agents for organic dust related disease. Am J Ind Med 1994; 25: 1-148.

11 Dalphin JC, Bildstein F, Pernet D, Dubiez A, Depierre A. Prevalence of chronic bronchitis and respiratory function in a group of dairy farmers in the French Doubs province. Chest 1989; 95: 1244-1247.

12 Dalphin JC, Dubiez A, Monnet E, et al. Prevalence of asthma and respiratory symptoms in dairy farmers in the French province of the Doubs. Am J Respir Crit Care Med 1998; 158: 1493-1498.

13 Chan-Yeung M, Dimich-Ward H, Enarson DA, Kennedy SM. Five cross-sectional studies of grain elevator workers. Am J Epidemiol 1992; 136: 1269-1279.

14 Ferris BG. Epidemiology standardization project (American Thoracic Society). Am Rev Respir Dis 1978; 118: Suppl. 6, 7-55.

15 Burney P, Luczynska C, Chinn S, Jarvis D. The European Community Respiratory Health Survey. Eur Respir J 1994; 7: 954-960.

16 Mauny F, Polio JC, Monnet E, et al. Longitudinal study of respiratory health in dairy farmers: influence of artificial barn fodder drying. Eur Respir J 1997; 10: 2522-2528.

17 Choma D, Westeel V, Dubiez A, et al. Etude de la fonction respiratoire en milieu agricole fourrager: influence respective des facteurs professionnels et de l'allergie. [Respiratory function parameters in dairy farmers: influence of occupational risk factors and allergy]. Rev Mal Resp 1998; 15: 765-772.
18 American Thoracic Society. Standardization of spirometry: 1987 update. Am Rev Respir Dis 1987; 136: 1285-1298.

19 Quanjer PH. Standardised lung function testing. Bull Eur Physiopath Respir 1983; 19: Suppl. 5, 1-95.

20 Braun-Fahrlander C. Environmental exposure to endotoxin and other microbial products and the decreased risk of childhood atopy: evaluating developments since April 2002. Curr Opin Allergy Clin Immunol 2003; 3: 325-329.

21 Pope CA, III, Dockery DW, Kanner RE, Villegas MG, Schwartz J. Oxygen saturation, pulse rate, and particulate air pollution. Am J Respir Crit Care Med 1999; 159: 365-372.

22 Cote CJ, Goldstein EA, Fuchsman NH, Hoaglin DC. The effects of nail polish on pulse oximetry. Anesth Analg 1988; 67: 683-686.

23 Dalphin JC, Debieuvre D, Pernet D, et al. A. Prevalence and risk factors for chronic bronchitis and farmer's lung in French dairy farmers. Br J Ind Med 1993; 50: 941-944.

24 Kullman GJ, Thorne PS, Waldron PF, et al. Organic dust exposures from work in dairy farmers. Am Ind Hyg Assoc J 1998; 59: 403-413.

25 Larsson K, Malmberg P, Eklund A, Belin L, Blaschke E. Exposure to microorganisms, airway inflammatory changes and immune reactions in asymptomatic dairy farmers. Int Arch Allergy Appl Immunol 1988; 87: 127-133.

26 Clapp WD, Becker S, Quay J, et al. Grain dust-induced airflow obstruction and inflammation of the lower respiratory tract. Am J Respir Crit Care Med 1994; 150: 611-617.

27 Nelms JD, Soper DJ. Cold vasodilatation and cold acclimatization in the hands of British fish filleters. J Appl Physiol 1962; 17: 444-448.

28 Goldsmith R. Cold exposure of farm and laboratory workers. J Appl Physiol 1967; 22: 47-49.

29 Sunyer J, Zock JP, Kromhout H, et al. Lung function decline, chronic bronchitis, and occupational exposures in young adults. Am Respir Crit Care Med 2005; 172: 1139-1145.

30 Burrows B, Lebowitz MD, Camilli AE, Knudson RJ. Longitudinal changes in forced expiratory volume in one second in adults. Am Rev Respir Dis 1986; 133: 974-980.

31 Glindmeyer HW, Diem JE, Jones RN, Weill H. Noncomparability of longitudinal and cross-sectionally determined annual change in spirometry. Am Rev Respir Dis 1982; 125: 544-548.

32 van Pelt W, Borsboom GJ, Rijcken B, Schouten JP, van Zomeren BC, Quanjer PH. Discrepancies between longitudinal and cross-sectional change in ventilatory function in 12 years of follow-up. Am J Respir Crit Care Med 1994; 149: 1218-1226.

33 Dalphin JC, Pernet D, Reboux G, et al. Influence of mode of storage and drying fodder on thermophilic actinomycete aerocontamination in dairy farms in the Doubs region of France. Thorax 1991; 46: 619-623.

34 Venier AG, Chaudemanche H, Monnet E, et al. Influence of occupational factors on lung function in French dairy farmers. A 5-year longitudinal study. Am J Ind Med 2006; 49: 231-237. 